\title{
The relationship between phase composition and conditions of sintering seawater derived magnesium oxide
}

\author{
J JAKIĆ* ${ }^{*}$ M LABOR and V MARTINAC \\ Faculty of Chemistry and Technology, University of Split, Ruđera Boškovića 35, 21000 Split, Croatia \\ e-mail: nina@ktf-split.hr
}

MS received 31 October 2017; revised 9 March 2018; accepted 22 March 2018; published online 27 June 2018

\begin{abstract}
This study has focused on the favourable effect of the $\mathrm{TiO}_{2}$ addition (1,2 and $5 \mathrm{wt} \%$ ) on the reduction of $\mathrm{B}_{2} \mathrm{O}_{3}$ content during activated sintering of magnesium oxide from seawater at temperatures of 1400 , 1500 and $1700^{\circ} \mathrm{C}$ for the duration of 1,2 and $4 \mathrm{~h}$. A mathematical model of dependence between the $\mathrm{B}_{2} \mathrm{O}_{3}$ mass fraction in the sintered sample, the temperature of isothermal sintering, the isothermal sintering time and the mass fraction of $\mathrm{TiO}_{2}$ added have been proposed. Magnesium oxide was obtained from seawater by substoichiometric precipitation, with the addition of $80 \%$ of dolomite lime as the precipitation agent. New phases formed in magnesium oxide samples were examined by the XRD and SEM/EDS analysis. The results indicate that during activated sintering of seawater-derived magnesium oxide with a $\mathrm{TiO}_{2}$ addition, reactions of formation of $\mathrm{Ca}_{2} \mathrm{~B}_{2} \mathrm{O}_{5}, \mathrm{CaTiO}_{3}$ and $\mathrm{Mg}_{2} \mathrm{TiO}_{4}$ took place simultaneously. The thermodynamics analysis of experimental results, based on the Onsager reciprocity relations (symmetry relations), was applied and phenomenological coefficients were calculated to describe the interference of these three irreversible processes.
\end{abstract}

Keywords. Sintering of $\mathrm{MgO}$; seawater; $\mathrm{TiO}_{2}$; mathematical model; Onsager's principle; phenomenological coefficients.

\section{Introduction}

Due to the reduction in magnesite reserves (in Great Britain and Japan), and consequently the ability to produce pure and high quality magnesium oxide, chemical processes for obtaining high purity magnesium oxide from seawater or saline waters rich with magnesium have been researched worldwide for a long time. A significant part of the world's production of synthetic magnesium oxide (by precipitation of magnesium hydroxide from seawater or salty waters) is nowadays produced in about twenty plants in industrially developed countries (China, France, Ireland, Israel, Jordan, South Korea, USA, Brazil, Mexico), amounting to about $14 \%$ of the world's production of magnesium [1]. Magnesium oxide has a number of applications in the industry and is used as an addition in the production of artificial fertilizers, as fillers in the manufacture of rubber, plastics, paper, magnesium, chemicals and medicines. Due to its excellent physical and chemical stability at high temperatures, sintered magnesium oxide has its wide application as a hightemperature refractory construction and insulating material. Seawater represents a major reservoir and an inexhaustible source of magnesium oxide due to the high mass concentration of magnesium in seawater, which averages $1.35 \mathrm{~g} \mathrm{dm}^{-3}$ i.e., $0.13 \%$ magnesium in the total mass of

*For correspondence seawater $[1,2]$. The precipitation of magnesium hydroxide from seawater with the addition of a lesser amount of the precipitation agent than stoichiometrically required still poses a challenge when it comes to the selection of the precipitation method and the starting raw material.

Magnesium oxide obtained from seawater by substoichiometric precipitation, with the addition of $80 \%$ of dolomite lime as the precipitation agent was used in the present study. The sintering process was conducted at temperatures of 1400,1500 and $1700^{\circ} \mathrm{C}$ for the duration of 1,2 and $4 \mathrm{~h}$ and the addition of 1,2 and $5 \mathrm{wt} \% \mathrm{TiO}_{2}$ with the purpose of establishing a mathematical model between the $\mathrm{B}_{2} \mathrm{O}_{3}$ mass fraction as the dependent variable and independent variables of the temperature of isothermal sintering, the isothermal sintering time and the mass fraction of the added $\mathrm{TiO}_{2}$.

The aim of this study was to investigate the correlations of sintering conditions and solid state reactions which take place simultaneously during the sintering of magnesium oxide from seawater.

\section{Experimental}

Seawater used for the precipitation of magnesium hydroxide in this study was taken from the location of the Oceanographic Institute in Split, Croatia. The composition 
of seawater, determined by the complexometric method [3], with respect to the contents of $\mathrm{MgO}$ and $\mathrm{CaO}$, was as follows:

$$
2.3293 \mathrm{~g} \mathrm{~L}^{-1} \mathrm{MgO} \text { and } 0.6229 \mathrm{~g} \mathrm{~L}^{-1} \mathrm{CaO}
$$

Dolomite lime was obtained by the calcination of dolomite (location Đipalo-Sinj, Croatia) at $950^{\circ} \mathrm{C}$ for $5 \mathrm{~h}$. The composition of dolomite lime used as the precipitation agent was as follows [4]:

$$
\begin{aligned}
& 40.69 \text { wt } \% \mathrm{MgO} ; 59.03 \text { wt } \% \mathrm{CaO} ; 0.1083 \text { wt } \% \mathrm{SiO}_{2} ; \\
& 0.0705 \text { wt } \% \mathrm{Fe}_{2} \mathrm{O}_{3} ; 0.0925 \text { wt } \% \mathrm{Al}_{2} \mathrm{O}_{3} .
\end{aligned}
$$

Seawater was pre-treated with sulphuric acid in order to remove bicarbonate $\left(\mathrm{HCO}_{3}{ }^{-}\right)$and carbonate $\left(\mathrm{CO}_{3}{ }^{2-}\right)$ ions, followed by the removal of the liberated carbon dioxide $\left(\mathrm{CO}_{2}\right)$ by aeration in a desorption tower. The flow rate of the induced air was $120 \mathrm{~L} \mathrm{~h}^{-1}$ and the volumetric flow rate of seawater through the desorption tower was $6 \mathrm{~L} \mathrm{~h}^{-1}$. After the pre-treatment of seawater, a calculated amount of dolomite lime was added to the magnesium hydroxide precipitate. The experiments were carried out with substoichiometric precipitation, with the addition of $80 \%$ of the stoichiometric quantity of dolomite lime.

The precipitation reaction took 30 min with magnetic stirring. Sedimentation was improved by the addition of the optimum amount $\left(6.8 \mathrm{~cm}^{3} / 2 \mathrm{~L}\right)$ of the anionic 818 A flocculent (polyacrylamide) produced by the Dutch firm Hercules. The optimum quantity of the anionic $818 \mathrm{~A}$ flocculent has already been described in a previous study $[5]$.

After sedimentation of the magnesium hydroxide precipitate, the precipitate was decanted and rinsed. Distilled water $(\mathrm{pH}=5.86)$ and alkalized distilled water $(\mathrm{pH}=12.50)$ were used as the rinsing agent. The rinsing by decanting used the combined rinsing method $(2+3)$, i.e., the magnesium hydroxide precipitate was rinsed 2 times by distilled water $(\mathrm{pH}=5.86)$ and 3 times by alkalized distilled water $(\mathrm{pH}=12.50)$. Rinsing by decanting was performed with about $1 \mathrm{dm}^{3}$ of the rinsing agent. The duration of contact with the rinsing agent was about $30 \mathrm{~min}$, i.e., until the precipitate settled again before the following decanting. After rinsing by decanting, the samples were rinsed in the process of filtering on multiple funnels using repeated rinsing (5 times) with distilled water $(\mathrm{pH}=5.86)$.

The rinsed precipitate was dried in an oven at $105^{\circ} \mathrm{C}$, and then calcined in a muffle furnace at $950^{\circ} \mathrm{C}$ for $5 \mathrm{~h}$ to form caustic magnesia.

The chemical composition of the magnesium oxide product $(80 \%$ precipitation) was: $98.98 \mathrm{wt} \% \mathrm{MgO}$, 0.83 wt $\% \mathrm{CaO}$ and $0.1888 \mathrm{wt} \% \mathrm{~B}_{2} \mathrm{O}_{3}$.

Mixtures of magnesium oxide were then prepared with the addition of mass fractions of $1 \%, 2 \%$ and $5 \% \mathrm{TiO}_{2}$. The doping oxide used was analytical reagent grade titanium $\left(\mathrm{TiO}_{2}\right.$ p.a.) in the rutile form-produced by Carlo Erba
Reagent. Samples were homogenized by manual stirring in absolute ethanol for $30 \mathrm{~min}$. The mixtures were dried at $80^{\circ} \mathrm{C}$ until all the alcohol was evaporated. Mixtures were cold pressed into compacts at a pressure of $625 \mathrm{MPa}$. Pressing was performed in a "Maschinenfabrik Herzog Osnabrück" hydraulic press, model TP 40. All compacts were sintered at temperatures of 1400,1500 and $1700^{\circ} \mathrm{C}$ for the duration of 1,2 and $4 \mathrm{~h}$. The time of reaching these temperatures in the gas furnace was about $2 \mathrm{~h}$. After sintering, samples were left to cool down in the furnace (type 553, French company "Mecker"). The boron content in the samples examined was determined using the potentiometric method. The variation coefficient for the method applied [6] is $\pm 1 \%$. Results represent the average number of measurements ( 5 analyses in each case).

Phase compositions were analysed by X-ray powder diffraction (program MAUD) [7] using an ItalStructures diffractometer APD2000 with monochromatised $\mathrm{Cu} \mathrm{Ka}$ radiation (graphite monochromator). Silicon (Koch-Light Lab. Ltd.) was used as an internal standard (space group $\mathrm{m} \overline{3} \mathrm{~m}$, for $\mathrm{a}=5.43088 \AA$ Á). The magnesium oxide samples were also examined by scanning electron microscopy (JSM-6510 LV, JEOL) equipped with an attached energy dispersive X-ray spectrometer (Oxford INCA X-act.) for the semi-quantitative elemental analysis.

\section{Results and discussion}

Table 1 shows the test results for the $\mathrm{B}_{2} \mathrm{O}_{3}$ mass fraction in sintered magnesium oxide samples with and without the $\mathrm{TiO}_{2}$ addition under the operating conditions described. The $\mathrm{B}_{2} \mathrm{O}_{3}$ mass fraction in sintered magnesium oxide samples changes with the change in the parameters of activated sintering. A significant decrease of the $\mathrm{B}_{2} \mathrm{O}_{3}$ content in sintered samples is observed after the addition of 2 mass $\% \mathrm{TiO}_{2}$ at all sintering temperatures from 1400 to $1700^{\circ} \mathrm{C}$ while the addition of 1 mass $\%$ has no major impact.

Table 1. The $\mathrm{B}_{2} \mathrm{O}_{3}$ content in $\mathrm{MgO}$ samples derived from seawater $\left(80 \%\right.$ precipitation) sintered at $1400,1500,1700^{\circ} \mathrm{C}$ for 1,2 and $4 \mathrm{~h}$ with different additions of $\mathrm{TiO}_{2}$.

\begin{tabular}{cccccc}
\hline \multicolumn{2}{l}{$\mathrm{MgO}(80 \%$ precipitation $)$} & & \multicolumn{3}{c}{$w\left(\mathrm{~B}_{2} \mathrm{O}_{3}\right), \mathrm{wt} \%$} \\
\cline { 1 - 3 } \cline { 5 - 6 } $\mathrm{t} /{ }^{\circ} \mathrm{C}$ & $\tau / \mathrm{h}$ & & $1 \% \mathrm{TiO}_{2}$ & $2 \% \mathrm{TiO}_{2}$ & $5 \% \mathrm{TiO}_{2}$ \\
\hline \multirow{2}{*}{1400} & 1 & 0.1805 & 0.0772 & 0.0582 \\
& 2 & & 0.1425 & 0.0364 & 0.0328 \\
\multirow{2}{*}{1500} & 4 & & 0.1239 & 0.0283 & 0.0273 \\
& 1 & & 0.0997 & 0.0270 & 0.0228 \\
\multirow{2}{*}{1700} & 2 & 0.0933 & 0.0206 & 0.0171 \\
& 4 & 0.0836 & 0.0154 & 0.0138 \\
& 1 & 0.0785 & 0.0174 & 0.0119 \\
& 2 & 0.0598 & 0.0106 & 0.0103 \\
& 4 & 0.0280 & 0.0087 & 0.0071 \\
\hline
\end{tabular}


Compared to the $\mathrm{B}_{2} \mathrm{O}_{3}$ mass fraction in calcined magnesium oxide sample, the percent of $\mathrm{B}_{2} \mathrm{O}_{3}$ evaporated from the sintered samples increases both with the increase of the duration of isothermal sintering and with the increase of the sintering temperature and the mass percent of $\mathrm{TiO}_{2}$ added. The results presented in table 1 have been analysed in order to perform the regression analysis to obtain a mathematical model.

The mathematical package 'Statistics 7' was used to perform the correlation and regression analysis of experimental data (table 1) in order to obtain the relationship between the $\mathrm{B}_{2} \mathrm{O}_{3}$ mass fraction in sintered $\mathrm{MgO}$ as the dependent variable and independent variables.

- temperature of isothermal sintering, $t$ : $1400^{\circ} \mathrm{C}$, $1500^{\circ} \mathrm{C}$, and $1700^{\circ} \mathrm{C}$,

- duration of isothermal sintering, $\tau$ : 1,2 , and $4 \mathrm{~h}$, and

- mass fraction of added $\mathrm{TiO}_{2}, z: 0,1,2$, and $5 \%$.

The correlation between the $\mathrm{B}_{2} \mathrm{O}_{3}$ mass percent $(w)$ and temperature $t$, duration of isothermal sintering $\tau$ and the mass fraction of added $\mathrm{TiO}_{2} z$ was examined. The results are shown in table 2. The correlation matrix (table 2) shows that, for examined magnesium oxide samples $(80 \%$ precipitation), there is no correlation between the temperature, duration or $\mathrm{TiO}_{2}$ mass fraction, and therefore a regression equation can be obtained. There exists a significant $(p=0.05)$ negative correlation of medium strength between the $\mathrm{B}_{2} \mathrm{O}_{3}$ mass fraction and temperature and between the $\mathrm{B}_{2} \mathrm{O}_{3}$ mass fraction and mass fraction of $\mathrm{TiO}_{2}$, and there exists a significant weak correlation between the $\mathrm{B}_{2} \mathrm{O}_{3}$ mass fraction and duration of isothermal sintering.

A model of multiple regressions has been proposed.

$$
w=\mathrm{b}_{o}+\mathrm{b}_{1} \cdot t+\mathrm{b}_{2} \tau+\mathrm{b}_{3} \cdot z+\mathrm{b}_{4} \cdot z^{2}+\varepsilon
$$

where $w$ is the mass fraction of $\mathrm{B}_{2} \mathrm{O}_{3}, t$ is the temperature $\left({ }^{\mathrm{o}} \mathrm{C}\right), \tau$ is the time of isothermal sintering $(\mathrm{h}), z$ is the mass fraction (\%) of added $\mathrm{TiO}_{2}, \mathrm{~b}_{\mathrm{o}}, \mathrm{b}_{1}, \mathrm{~b}_{2}, \mathrm{~b}_{3}, \mathrm{~b}_{4}$ are unknown coefficients and $\varepsilon$ is the random error in the model.

The regression equations:

$$
\begin{aligned}
w= & 0.45598-0.000207 \cdot t-0.009356 \tau-0.04868 \cdot z \\
& +0.005882 \cdot z
\end{aligned}
$$

where $\mathrm{s}=0.02588 ; \quad \mathrm{R}^{2}=0.76525 ; \quad \mathrm{R}=0.87478 ; \quad \mathrm{F}(4$, 139) $=113.28 ; \mathrm{p}=0.00$.

The value of the multiple correlation coefficient indicates that $87.5 \%$ of the $\mathrm{B}_{2} \mathrm{O}_{3}$ mass fraction variation may be attributed to the effect of variation of these factors: temperature, duration and mass percent of the $\mathrm{TiO}_{2}$ addition. Only $12.5 \%$ of the $\mathrm{B}_{2} \mathrm{O}_{3}$ mass fraction variation is due to some other factors and random influences. Consequently, the proposed model is acceptable for predicting the $\mathrm{B}_{2} \mathrm{O}_{3}$ mass fraction in the temperature range $1400-1700^{\circ} \mathrm{C}$, duration of isothermal sintering $1-4 \mathrm{~h}$ and the $\mathrm{TiO}_{2}$ addition from $0-5 \%$ because the statistic $\mathrm{F}$ is significant at the level of $\mathrm{p}=0.00$.

Earlier research [8-10] has already shown a positive effect of the $\mathrm{TiO}_{2}$ addition on the $\mathrm{B}_{2} \mathrm{O}_{3}$ content in sintered $\mathrm{MgO}$ samples, due to $\mathrm{CaTiO}_{3}$ formation during sintering. The $\mathrm{TiO}_{2}$ reaction with $\mathrm{CaO}$ reduces the amount of $\mathrm{CaO}$ available to react with $\mathrm{B}_{2} \mathrm{O}_{3}$, therefore a higher amount of $\mathrm{B}_{2} \mathrm{O}_{3}$ can evaporate during the sintering process. The increase in temperature and duration of sintering also increases the percentage of evaporation of $\mathrm{B}_{2} \mathrm{O}_{3}$ from the samples into the atmosphere. According to Hesmanu [11] good quality sintered magnesium oxide used in the refractory industry contains $\leq 0.05$ mass $\% \quad \mathrm{~B}_{2} \mathrm{O}_{3}$. This condition is met already at lower sintering temperatures $\left(1400^{\circ} \mathrm{C}\right)$ with the addition of 2 mass $\% \mathrm{TiO}_{2}$ or 5 mass $\%$ $\mathrm{TiO}_{2}$ depending on the sintering duration [10].

The results of the phase analysis at 1500 and $1700^{\circ} \mathrm{C}$ for $4 \mathrm{~h}$ (figures 1 and 2) obtained by the XRD analysis show periclase to be the main crystalline phase in all the samples. In the sample without any addition no other phase was detected. It is assumed that the amounts of $\mathrm{CaO}$ and $\mathrm{B}_{2} \mathrm{O}_{3}$ in this sample are too small to be detected by the XRD analysis. In a previous study [12], it has been found that $\mathrm{B}_{2} \mathrm{O}_{3}$ reacts with $\mathrm{CaO}$ during sintering to form $\mathrm{Ca}_{2} \mathrm{~B}_{2} \mathrm{O}_{5}$. The addition of $\mathrm{TiO}_{2}$ leads to formation of $\mathrm{CaTiO}_{3}$ and $\mathrm{MgTiO}_{4}$ which has been detected by the XRD analysis. The microstructural effect of titania addition to magnesium oxide from seawater is evident from figures 3 and 4 . A certain quantity of $\mathrm{CaTiO}_{3}$ and $\mathrm{Mg}_{2} \mathrm{TiO}_{4}$ appeared in the form of globular segregations within the grains of $\mathrm{MgO}$. The addition of $\mathrm{TiO}_{2}$ to seawater derived magnesia results in the formation of small quantities reactive liquid that promotes sintering and grain growth. The SEM/EDS analysis (figures 3 and 4) of $\mathrm{MgO}$ samples detected the

Table 2. The correlation matrix for $\mathrm{MgO}$ ( $80 \%$ precipitation) samples.

\begin{tabular}{lcccc}
\hline & \multicolumn{4}{c}{ Correlation for $\mathrm{MgO}(80 \%$ precipitation) samples } \\
\cline { 2 - 5 } Variable & $t /{ }^{\circ} \mathrm{C}$ & $\tau / \mathrm{h}$ & $\mathrm{TiO}_{2}$ addition, wt $\%,(z)$ & -0.00 \\
\hline$t /{ }^{\circ} \mathrm{C}$ & 1.00 & 0.00 & 0.00 & -0.49 \\
$\tau / \mathrm{h}$ & 0.00 & 1.00 & 1.00 & -0.22 \\
$\mathrm{TiO}_{2}$ addition, wt $\%$ & -0.00 & 0.00 & -0.63 & 1.00 \\
$\mathrm{~B}_{2} \mathrm{O}_{3}, \mathrm{wt} \%$ & -0.49 & -0.22 & $\mathrm{~B} \mathrm{O}_{3}, \mathrm{wt} \%,(w)$ \\
\hline
\end{tabular}



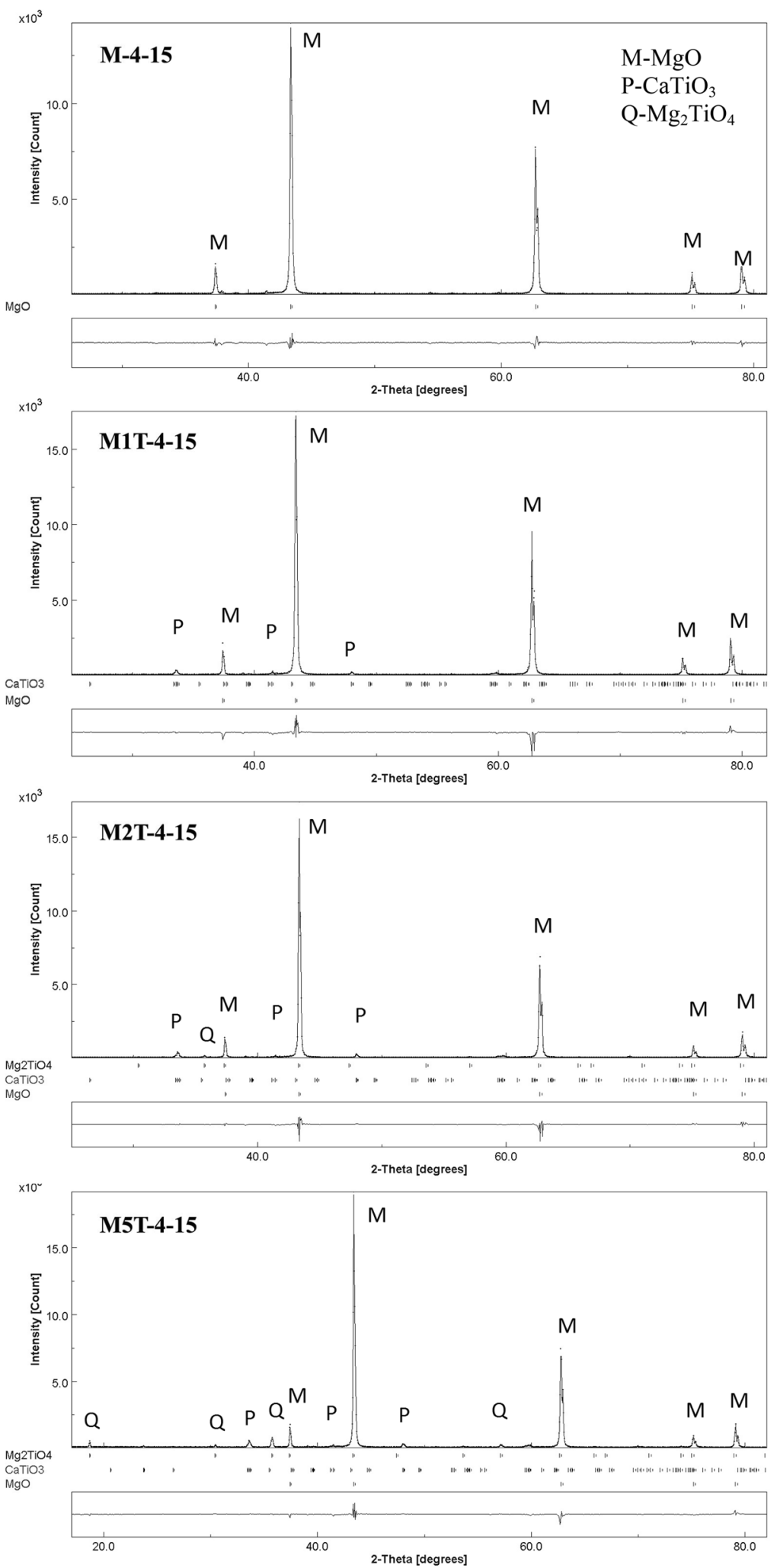

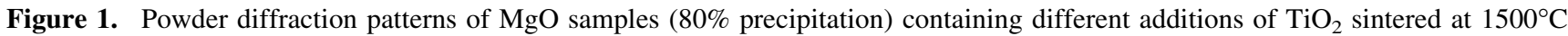
for $4 \mathrm{~h}$. (M-4-15- $\mathrm{MgO}$ without any addition of $\mathrm{TiO}_{2}$ sintered at $1500^{\circ} \mathrm{C} / 4 \mathrm{~h} ; \mathrm{M} 1 \mathrm{~T}-4-15-\mathrm{MgO}$ with the addition of $1 \% \mathrm{TiO}{ }_{2}$ sintered at $1500^{\circ} \mathrm{C} / 4 \mathrm{~h}$; $\mathrm{M} 2 \mathrm{~T}-4-15-\mathrm{MgO}$ with the addition of $2 \% \mathrm{TiO}_{2}$ sintered at $1500^{\circ} \mathrm{C} / 4 \mathrm{~h}$; $\mathrm{M} 5 \mathrm{~T}-4-15-\mathrm{MgO}$ with the addition of $5 \% \mathrm{TiO}{ }_{2}$ sintered at $1500^{\circ} \mathrm{C} / 4 \mathrm{~h}$ ). 

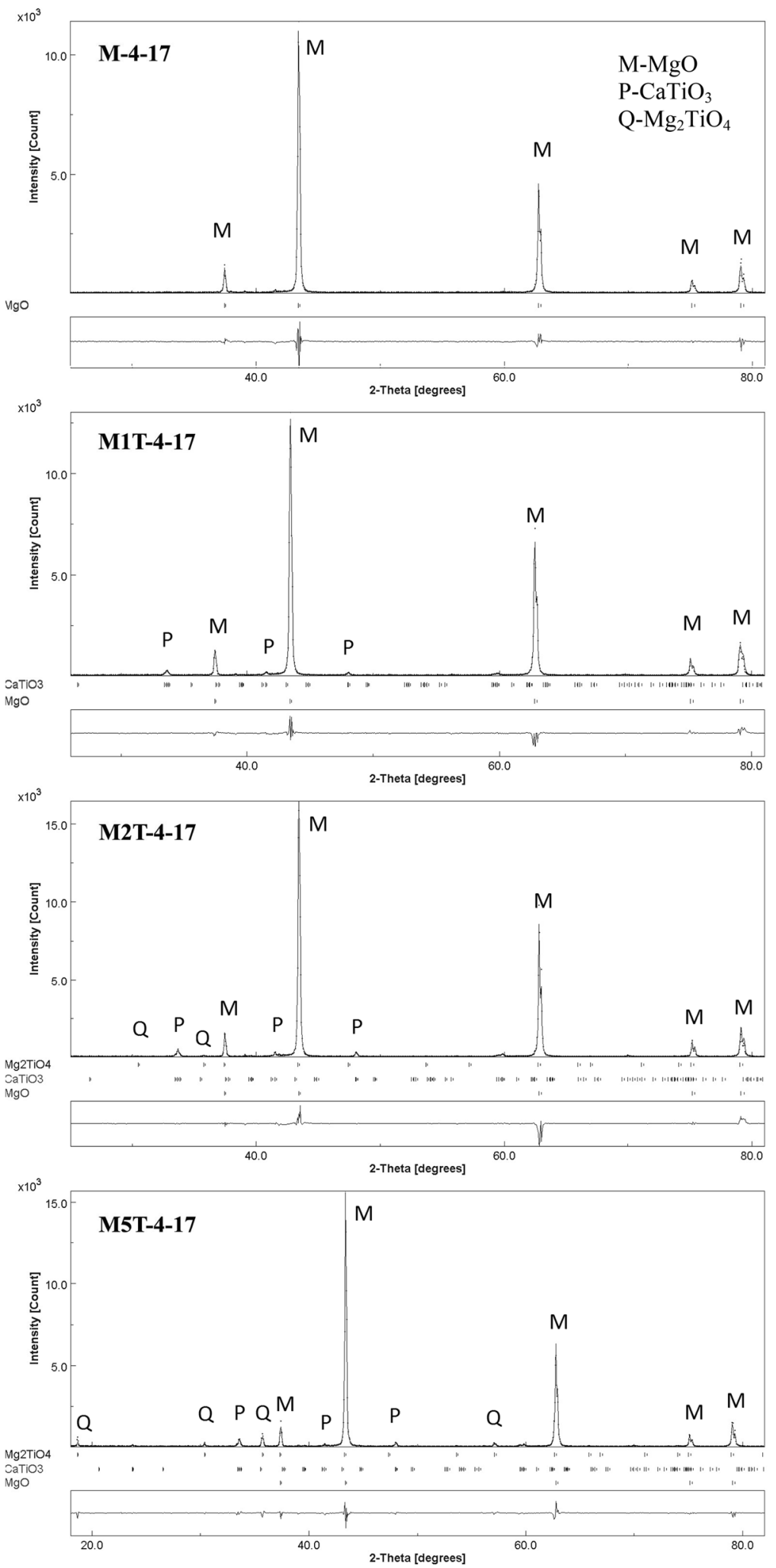

Figure 2. Powder diffraction patterns of $\mathrm{MgO}$ samples $\left(80 \%\right.$ precipitation) containing different additions of $\mathrm{TiO}_{2}$ sintered at $1700^{\circ} \mathrm{C}$ for $4 \mathrm{~h}$. (M-4-17- $\mathrm{MgO}$ without any addition of $\mathrm{TiO}_{2}$ sintered at $1700^{\circ} \mathrm{C} / 4 \mathrm{~h} ; \mathrm{M} 1 \mathrm{~T}-4-17-\mathrm{MgO}$ with the addition of $1 \% \mathrm{TiO}_{2}$ sintered at $1700^{\circ} \mathrm{C} / 4 \mathrm{~h}$; $\mathrm{M} 2 \mathrm{~T}-4-17-\mathrm{MgO}$ with the addition of $2 \% \mathrm{TiO}_{2}$ sintered at $1700^{\circ} \mathrm{C} / 4 \mathrm{~h}$; $\mathrm{M} 5 \mathrm{~T}-4-17-\mathrm{MgO}$ with the addition of $5 \% \mathrm{TiO}{ }_{2}$ sintered at $1700^{\circ} \mathrm{C} / 4 \mathrm{~h}$ ). 
presence of $\mathrm{CaO}$ and confirmed the results obtained by the XRD analysis. The chemical analysis detected the presence of $\mathrm{CaO}$ and $\mathrm{B}_{2} \mathrm{O}_{3}$ as impurities.

In previous study [9] we have studied the mutual relationship of two interdependent reactions, i.e., reactions of formation of $\mathrm{Ca}_{2} \mathrm{~B}_{2} \mathrm{O}_{5}$ and $\mathrm{CaTiO}_{3}$ so that this study is a continuous investigation with the purpose to connect all the factors that take effect on sintering of magnesium oxide from seawater.

Since the results of the XRD analysis indicated the formation of the $\mathrm{Mg}_{2} \mathrm{TiO}_{4}$ phase, the system of two interdependent reactions of formation of $\mathrm{Ca}_{2} \mathrm{~B}_{2} \mathrm{O}_{5}$ and $\mathrm{CaTiO}_{3}$ has been extended to include the reaction of formation of $\mathrm{Mg}_{2} \mathrm{TiO}_{4}$. Thus, during the process of activated sintering of seawater-derived $\mathrm{MgO}$ with the addition of $\mathrm{TiO}_{2}$, three interdependent reactions take place:
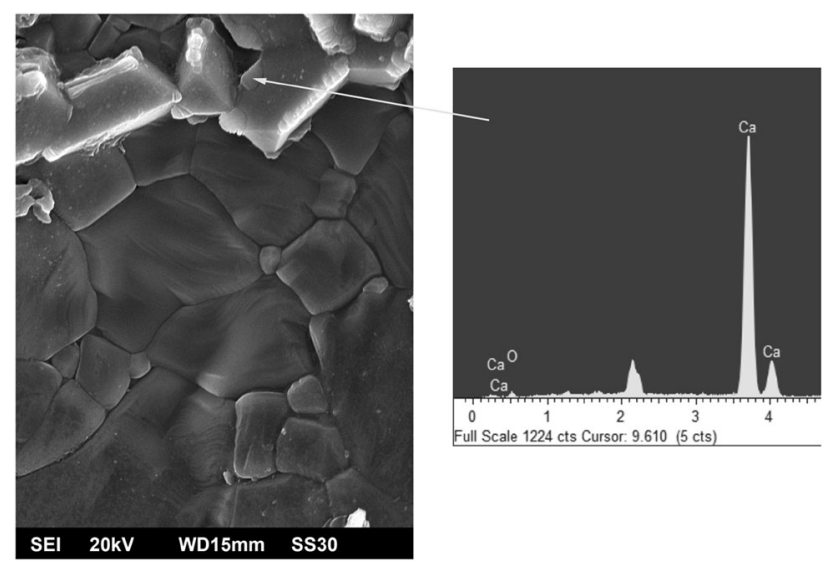

Figure 3. SEM/EDS images of the $\mathrm{MgO}$ sample without any addition of $\mathrm{TiO}_{2}$ sintered at $1700^{\circ} \mathrm{C} / 4 \mathrm{~h}$.

$$
\begin{gathered}
2 \mathrm{CaO}+\mathrm{B}_{2} \mathrm{O}_{3} \rightarrow \mathrm{Ca}_{2} \mathrm{~B}_{2} \mathrm{O}_{5} \\
\mathrm{CaO}+\mathrm{TiO}_{2} \rightarrow \mathrm{CaTiO}_{3} \\
2 \mathrm{MgO}+\mathrm{TiO}_{2} \rightarrow \mathrm{Mg}_{2} \mathrm{TiO}_{4}
\end{gathered}
$$

The consideration of the above mentioned three relationships has not been reported in literature. A system of phenomenological equations, dealt within the open system thermodynamics [13-16], has been applied to reactions (3), (4), and (5) in order to link all the factors affecting the process of activated sintering of seawater-derived magnesium oxide, and the ability to control the process itself.

The non-equilibrium thermodynamics approach is widely recognized as a useful phenomenological theory that describes the coupled transport without the need for examining detailed coupling mechanisms of complex processes. The principles of non-equilibrium thermodynamics for the systems not far away from the thermodynamic equilibrium are expressed in linear forms [13-15]. Linear relations can be expressed between flows $J_{i}$, and driving forces $X_{i}$. If a non-equilibrium system consists of several flows caused by various forces, the general expression for $J_{i}$ is:

$$
J_{i}=\sum_{j}^{n} L_{i j} \cdot X_{j} \quad(i, j=1,2, \ldots, \mathrm{n})
$$

or for $X_{i}$

$$
X_{i}=\sum_{j}^{n} K_{i j} \cdot J_{j} \quad(i, j=1,2, \ldots, \mathrm{n})
$$

where: $L_{i j}, K_{i j}$ are phenomenological coefficients. Equations (6) and (7) are phenomenological equations which
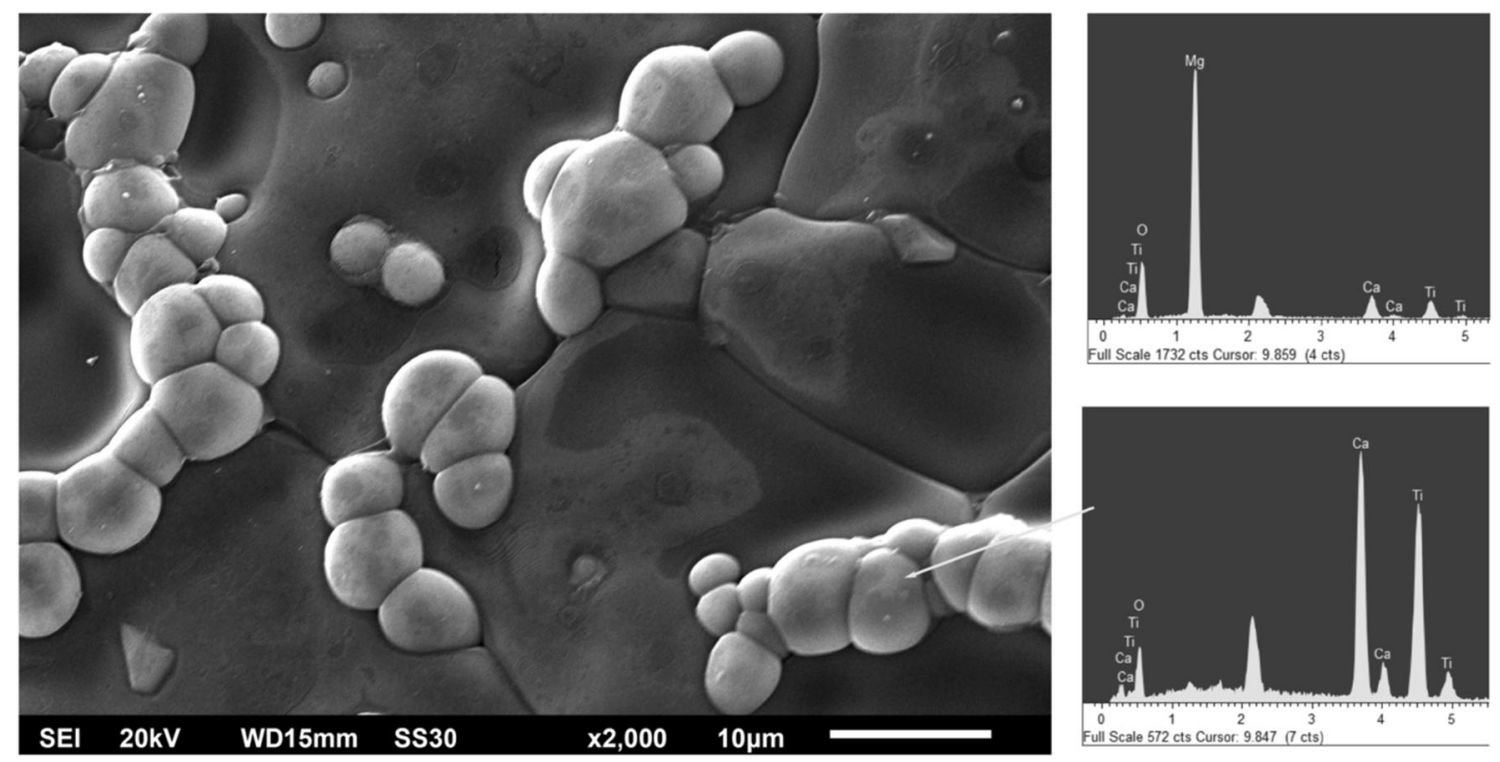

Figure 4. SEM/EDS images of the $\mathrm{MgO}$ sample with the addition of $5 \% \mathrm{TiO}_{2}$ sintered at $1700^{\circ} \mathrm{C} / 4 \mathrm{~h}$. 
describe the multi-flow systems and the effect of nonconjugate forces on a flow. The "proper" phenomenological coefficients with the same indices relate the conjugated forces and flows. The "mutual" phenomenological coefficients $L_{i j}$ or $K_{i j}(i \neq j)$ describe the interference, i.e., characterize the mutual effect of the two irreversible processes " $\mathrm{i}$ " and " $\mathrm{j}$ ". According to the principle of microscopic reversibility, Onsager has defined "mutual" phenomenological coefficients and postulated that the matrix of "mutual" phenomenological coefficients is symmetrical [16].

$$
\begin{aligned}
& L_{i j}=L_{j i} \text { i.e. }\left(\frac{\partial J_{i}}{\partial X_{j}}\right)_{X_{i=0}, i \neq j}=\left(\frac{\partial J_{j}}{\partial X_{i}}\right)_{X_{j=0}, i \neq j}(i, j=1,2, \ldots, \mathrm{n}) \\
& K_{i j}=K_{j i} \text { i.e. }\left(\frac{\partial X_{i}}{\partial J_{j}}\right)_{J_{i=0, i \neq j}}=\left(\frac{\partial X_{j}}{\partial J_{i}}\right)_{J_{j=0}, i \neq j}(i, j=1,2, \ldots, \mathrm{n})
\end{aligned}
$$

The system of these three interdependent reactions has been analysed by linear non-equilibrium thermodynamics, based on an important theorem due to Onsager. For a system with three flows caused by three driving forces, i.e., with three simultaneous irreversible processes $(n=3)$, phenomenological equations can be expressed based on Onsager reciprocity relations [13-15]:

$$
\begin{aligned}
& J_{1}=L_{11} X_{1}+L_{12} X_{2}+L_{13} X_{3} \\
& J_{2}=L_{21} X_{1}+L_{22} X_{2}+L_{23} X_{3} \\
& J_{3}=L_{31} X_{1}+L_{32} X_{2}+L_{33} X_{3}
\end{aligned}
$$

where $J_{1}, J_{2}$ and $J_{3}$ denote the flows; and $X_{1}, X_{2}$ and $X_{3}$ denote the forces causing these flows. The "mutual" coefficients are equal according to Equations (8) and (9), which reduces the number of phenomenological coefficients. The phenomenological coefficients have to meet the following conditions [15]:

$$
\begin{gathered}
L_{11} \geq 0, L_{22} \geq 0, L_{33} \geq 0 \\
L_{11} L_{22}-\frac{1}{4}\left(L_{12}+L_{21}\right)^{2} \geq 0 \\
L_{22} L_{33}-\frac{1}{4}\left(L_{23}+L_{32}\right)^{2} \geq 0 \\
L_{11} L_{33}-\frac{1}{4}\left(L_{13}+L_{31}\right)^{2} \geq 0
\end{gathered}
$$

The "proper" coefficients are always positive because the entropy production can never be negative. The "mutual" coefficients are limited by Equations (14), (15) and (16). The matrix of phenomenological coefficients $L_{i j}$ and $K_{i j}$, is related by

$$
K=L^{-1}
$$

where $L^{-1}$ is the inverse of the matrix $L$.

The phenomenological equations can also be expressed in terms of forces:

$$
\begin{aligned}
& X_{1}=K_{11} J_{1}+K_{12} J_{2}+K_{13} J_{3} \\
& X_{2}=K_{21} J_{1}+K_{22} J_{2}+K_{23} J_{3} \\
& X_{3}=K_{31} J_{1}+K_{32} J_{2}+K_{33} J_{3}
\end{aligned}
$$

The phenomenological coefficients are related by the following relations:

$$
\begin{aligned}
& K_{11}=\frac{\left(L_{22} L_{33}-L_{23}^{2}\right)}{|L|} ; K_{22}=\frac{\left(L_{11} L_{33}-L_{13}^{2}\right)}{|L|} ; \\
& K_{33}=\frac{\left(L_{11} L_{22}-L_{12}^{2}\right)}{|L|} ; K_{12}=\frac{\left(L_{13} L_{23}-L_{12} L_{33}\right)}{|L|} ; \\
& K_{13}=\frac{\left(L_{12} L_{23}-L_{22} L_{13}\right)}{|L|} ; K_{23}=\frac{\left(L_{13} L_{12}-L_{23} L_{11}\right)}{|L|} \\
& L=L_{11} L_{22} L_{33}+2 L_{12} L_{13} L_{23}-L_{13}^{2} L_{22}-L_{23}^{2} L_{11}-L_{12}^{2} L_{33}
\end{aligned}
$$

where $|\mathrm{L}|$ is the determinant of the matrix $\mathrm{L}$.

Coefficients $L_{12}, L_{23}$ and $L_{13}$ have been calculated from Equations (10), (11), (12), (13), (14), (15) and (16) using the mathematical program Wolfram Alpha. They are defined as:

$$
\begin{aligned}
& L_{12}=\frac{J_{1} J_{2}}{J_{1} X_{1}+J_{2} X_{2}-J_{3} X_{3}} ; \\
& L_{23}=\frac{J_{2} J_{3}}{-J_{1} X_{1}+J_{2} X_{2}+J_{3} X_{3}} ; \\
& L_{13}=\frac{J_{1} J_{3}}{J_{1} X_{1}-J_{2} X_{2}+J_{3} X_{3}}
\end{aligned}
$$

or

$$
\begin{aligned}
& L_{12}=\frac{J_{1} J_{2}}{J_{1} X_{1}+J_{2} X_{2}+J_{3} X_{3}} ; \\
& L_{23}=\frac{J_{2} J_{3}}{J_{1} X_{1}+J_{2} X_{2}+J_{3} X_{3}} ; \\
& L_{13}=\frac{J_{1} J_{3}}{J_{1} X_{1}+J_{2} X_{2}+J_{3} X_{3}}
\end{aligned}
$$

Equations (23) and (24) give different results for the same coefficient but the result used in further calculation is the one that gives a better match at the end of the experiment. The combination of the mean values method with the least square method was used in determining all the phenomenological coefficients. Coefficients $L_{22}, L_{33}$ and $L_{11}$ have been calculated using the mathematical program Mathcad 2000 Professional from Equations (10), (11) and (12). They are defined as: 


$$
\begin{aligned}
& L_{11}=\frac{\sum_{i, j} J_{1} X_{1}-L_{12} \sum_{i, j} X_{1} X_{2}-L_{13} \sum_{i, j} X_{1} X_{3}}{\sum_{i, j} X_{1}^{2}} ; \\
& L_{22}=\frac{\sum_{i, j} J_{2} X_{2}-L_{12} \sum_{i, j} X_{3} X_{2}-L_{23} \sum_{i, j} X_{2} X_{3}}{\sum_{i, j} X_{2}^{2}} ; \\
& L_{33}=\frac{\sum_{i, j} J_{3} X_{3}-L_{13} \sum_{i, j} X_{1} X_{3}-L_{23} \sum_{i, j} X_{2} X_{3}}{\sum_{i, j} X_{3}^{2}}
\end{aligned}
$$

If phenomenological equations (10), (11) and (12) are applied to the three reactions (3), (4) and (5) that describe the process of sintering of $\mathrm{MgO}$ samples ( $80 \%$ precipitation) obtained from seawater, it follows:

$$
\begin{aligned}
& J_{1}=L_{11} t^{\prime}+L_{12} \tau+L_{13} \gamma \\
& J_{2}=L_{21} t^{\prime}+L_{22} \tau+L_{23} \gamma \\
& J_{3}=L_{31} t^{\prime}+L_{32} \tau+L_{33} \gamma
\end{aligned}
$$

where $J_{1}$ represents the fraction of $\mathrm{B}_{2} \mathrm{O}_{3}$ evaporated, $J_{2}$ the fraction of $\mathrm{CaO}$ that reacts with $\mathrm{TiO}_{2}$ and $J_{3}$ the fraction of $\mathrm{TiO}_{2}$ that reacts with $\mathrm{MgO}$. These fractions are a function of the temperature of sintering $\left(t^{\prime}\right)$, time $(\tau)$ and additives $(\gamma)$. According to Equations (23), (24) and (25), phenomenological coefficients were calculated by using the experimental data shown in table 1. The theoretical approximation for $J_{1}, J_{2}$ and $J_{3}$ is replaced with the experimental results for $J_{1}^{\circ}, J_{2}^{\circ}$ and $J_{3}^{\circ}$. It has also been assumed that $t^{\prime}=t \cdot 10^{-2}{ }^{\circ} \mathrm{C}$ to achieve the appropriate adjustment of numerical expressions obtained. The obtained values for $J_{1}^{\circ}, J_{2}^{\circ}$ and $J_{3}^{\circ}$ are shown in table 3 .

After calculating all the phenomenological coefficients, phenomenological equations result in two sets of solutions (first set-29a, 30a, and 31a; second set-29b, 30b, and 31b).

$$
\begin{gathered}
J_{1}=1.625 \cdot t^{\prime}+4.707 \cdot \tau+0.126 \cdot \gamma \\
J_{1}=1.626 \cdot t^{\prime}+4.676 \cdot \tau+0.089 \cdot \gamma \\
J_{2}=4.707 \cdot t^{\prime}+7.781 \cdot \tau-0.144 \cdot \gamma \\
J_{2}=4.676 \cdot t^{\prime}+7.774 \cdot \tau+0.101 \cdot \gamma \\
J_{3}=0.126 \cdot t^{\prime}-0.144 \cdot \tau+0.153 \cdot \gamma \\
J_{3}=0.089 \cdot t^{\prime}+0.101 \cdot \tau+0.153 \cdot \gamma
\end{gathered}
$$

Relative errors are shown in table 4. The deviations of the theoretical data and the corresponding experimental data in both cases are within the reasonable limits because the relative errors for individual equations are relatively

\begin{tabular}{|c|c|c|c|c|c|c|c|c|c|c|}
\hline \multicolumn{11}{|c|}{$\mathrm{MgO}(80 \%$ precipitation) } \\
\hline \multirow[b]{2}{*}{$\mathrm{t} /{ }^{\circ} \mathrm{C}$} & \multirow[b]{2}{*}{$\tau / \mathrm{h}$} & \multicolumn{3}{|c|}{$\mathrm{MgO}+1 \% \mathrm{TiO}_{2}$} & \multicolumn{3}{|c|}{$\mathrm{MgO}+2 \% \mathrm{TiO}_{2}$} & \multicolumn{3}{|c|}{$\mathrm{MgO}+5 \% \mathrm{TiO}_{2}$} \\
\hline & & $J_{1}^{\circ}$ & $\begin{array}{r}J_{2}{ }^{\circ} \\
\text { wt } \%\end{array}$ & $J_{3}^{\circ}$ & $J_{1}^{\circ}$ & $\begin{array}{r}J_{2}{ }^{\circ} \\
\mathrm{wt} \%\end{array}$ & $J_{3}^{\circ}$ & $J_{1}^{\circ}$ & $\begin{array}{r}J_{2}{ }^{\circ} \\
\text { wt } \%\end{array}$ & $J_{3}^{\circ}$ \\
\hline \multirow[t]{3}{*}{1400} & 1 & 4.40 & 64.75 & 0.20 & 59.11 & 84.69 & 0.85 & 69.17 & 88.36 & 3.40 \\
\hline & 2 & 24.52 & 72.09 & 0.12 & 80.72 & 92.57 & 0.77 & 82.63 & 93.26 & 3.35 \\
\hline & 4 & 34.38 & 75.68 & 0.09 & 85.01 & 94.13 & 0.76 & 85.54 & 94.32 & 3.33 \\
\hline \multirow[t]{3}{*}{1500} & 1 & 47.19 & 79.39 & 0.04 & 85.70 & 93.26 & 0.75 & 87.92 & 94.06 & 3.29 \\
\hline & 2 & 50.58 & 80.61 & 0.03 & 89.09 & 94.48 & 0.73 & 90.94 & 95.15 & 3.28 \\
\hline & 4 & 55.72 & 82.46 & 0 & 91.84 & 95.47 & 0.72 & 92.69 & 95.78 & 3.28 \\
\hline \multirow[t]{3}{*}{1700} & 1 & 58.42 & 82.46 & 0 & 90.78 & 94.41 & 0.72 & 93.70 & 95.45 & 3.22 \\
\hline & 2 & 68.33 & 82.46 & 0 & 94.39 & 95.69 & 0.70 & 94.54 & 95.75 & 3.22 \\
\hline & 4 & 85.17 & 82.46 & 0 & 95.39 & 96.05 & 0.70 & 96.24 & 96.36 & 3.21 \\
\hline
\end{tabular}
small. Equations (29a), (30a), (31a) match the experimental values better than equations (29b), (30b), (31b) and give slightly more accurate results. Therefore equations (29a), (30a), (31a) are more appropriate for this technological process of sintering $\mathrm{MgO}$ samples (80\% precipitation) obtained from seawater.

These phenomenological equations can also be expressed in terms of forces for the final results:

Table 4. Relative errors for individual values of all flows.

\begin{tabular}{lcccccccc}
\hline $\mathrm{MgO}(80 \%$ precipitation $)$ \\
\hline Relative errors/\% & \multicolumn{2}{l}{ First set of results } & & \multicolumn{3}{l}{ Second set of results } \\
\cline { 2 - 4 } \cline { 6 - 8 } & $J_{1}$ & $J_{2}$ & $J_{3}$ & & $J_{1}$ & $J_{2}$ & $J_{3}$ \\
\hline $\bar{\delta}$ & 0.69 & 0.12 & 6.44 & & 0.69 & 0.12 & 6.20
\end{tabular}

Table 3. The experimental values of $J_{1}^{o}, J_{2}^{o}$ and $J_{3}^{o}$ in dependence on temperature, duration of heating and additions of $\mathrm{TiO}_{2}$. 


$$
\begin{gathered}
t^{\prime}=-0.656 \cdot J_{1}+0.414 \cdot J_{2}+0.928 \cdot J_{3} \\
\tau=0.414 \cdot J_{1}-0.131 \cdot J_{2}-0.463 \cdot J_{3} \\
\gamma_{3}=0.928 \cdot J_{1}-0.463 \cdot J_{2}+5.325 \cdot J_{3}
\end{gathered}
$$

The phenomenological equations allow the usage of computer programs in order to predict the $\mathrm{B}_{2} \mathrm{O}_{3}$ content in sintered samples and the phase composition in the final product of $\mathrm{MgO}$ in dependence on temperature, duration of heating and additives. Modelling the process of sintering $\mathrm{MgO}$ from seawater is most important for predicting the content of $\mathrm{B}_{2} \mathrm{O}_{3}$ in the final product because the content of $\mathrm{B}_{2} \mathrm{O}_{3}$ has to be $\leq 0.05 \mathrm{wt} \%$ for getting the good quality refractory materials based on $\mathrm{MgO}$ [11].

\section{Conclusions}

The proposed mathematical model is acceptable for predicting the $\mathrm{B}_{2} \mathrm{O}_{3}$ mass fraction in the temperature interval $1400-1700^{\circ} \mathrm{C}$, duration of isothermal heating $1-4 \mathrm{~h}$ and the $\mathrm{TiO}_{2}$ addition of $0-5 \%$.

The concept of non-equilibrium thermodynamics has been successfully applied to the process of sintering $\mathrm{MgO}$ from seawater in order to establish the relations of mutual influence of simultaneous irreversible processes during sintering. The phenomenological equations are defined with phenomenological coefficients in dependence on temperature, duration of heating and additives. This relationship among all the factors of sintering makes it possible to use computer programs to predict the $\mathrm{B}_{2} \mathrm{O}_{3}$ content in the sintered samples and the phase composition in the final product of $\mathrm{MgO}$.

The phenomenological coefficients were calculated from the experimental data in the temperature range of $1400-1700^{\circ} \mathrm{C}$ for the duration of $1-4 \mathrm{~h}$ and with the addition of $\max 5 \%$ of $\mathrm{TiO}_{2}$. Since the same phenomenological coefficients have given dual results, relative errors were taken as an indicator of accuracy of the proceedings. As the values of relative errors were similar for both the results obtained, the phenomenological equations that are in better agreement with the experimental values obtained were chosen as more appropriate for the description of this technological process of sintering of $\mathrm{MgO}$ (80\% precipitation) obtained from seawater.

\section{Nomenclature}

$J_{\mathrm{i}}, J_{\mathrm{j}} \quad$ flows

$L_{\mathrm{ij}}, K_{\mathrm{ij}}$ phenomenological coefficients

$\begin{array}{ll}X_{\mathrm{i}}, X_{\mathrm{j}} & \begin{array}{l}\text { driving forces } \\ t^{\prime}\end{array} \\ \tau & \begin{array}{l}\text { temperature of sintering, }{ }^{\circ} \mathrm{C} \\ \text { time, } \mathrm{h}\end{array} \\ \gamma & \text { addition of } \mathrm{TiO}_{2}, \mathrm{wt} \%\end{array}$

\section{References}

[1] Shand M A 2006 The Chemistry and Technology of Magnesia. New York: Wiley, pp. 39-60

[2] Brown E, Colling A, Park D, Philips J, Rothery D and Wright J 1997 Seawater: Its Composition, Properties and Behaviour, 2nd edn. England: Butterworth Heinemann, p. 86

[3] Grasshoff K, Kremling K and Ehrhardt M 1999 Methods of Seawater Analysis. Weinheim: Wiley-VCH, pp. 193-212

[4] Jakić J, Labor M and Martinac V 2016 Characterization of dolomitic lime as based reagent for the precipitation $\mathrm{Mg}(\mathrm{OH})_{2}$ from seawater. Chem. Biochem. Eng. Q. 30: 373-379

[5] Petric N, Martinac V, Labor M and Jurin O 1999 Effect of $818 \mathrm{~A}$ and $827 \mathrm{~N}$ flocculants on seawater magnesia process. KZLTET. 33: 473-478

[6] Culkin F 1975 The Major Constituents of Seawater. Chemical OCEANOGRAPHY, vol. 1., Riley J P and Skirow G (Eds.), London: Academic Press, pp. 136-151

[7] Lutterotti L, Matthies S and Wenk H-R, 1999 MAUD (Material Analysis Using Diffraction). In: Proceeding of the 12th International Conference on Textures of Materials preceded (ICOTOM-12), pp.1599-1604

[8] Martinac V, Labor $\mathrm{M}$ and Petric $\mathrm{N} 2006 \mathrm{~B}_{2} \mathrm{O}_{3}$ and $\mathrm{CaO}$ in magnesium oxide from seawater. Mater. Tehnol. 40: 65-68

[9] Labor M, Martinac V and Petric N $2013 \mathrm{~B}_{2} \mathrm{O}_{3}$ content in the sintered magnesium oxide obtained from seawater. Indian $\mathrm{J}$. Chem. Technol. 20: 276-281

[10] Jakić J, Štefanić G, Labor M and Martinac V 2017 Microstructural characteristic of low-temperature $\left(1400{ }^{\circ} \mathrm{C}\right)$ sintered $\mathrm{MgO}$ obtained from seawater. Sci. Sinter. 49: 61-71

[11] Heasman N, 1979 New developments in seawater magnesia. Gas Wärme International 28: 392-397

[12] Petric N, Petric B, Tkalčec E, Martinac V, Bogdanić N and Mirošević-Anzulović M 1987 Effect of additives on sintering of magnesium oxide obtained from sea water. Sci. Sinter. 19: $81-87$

[13] Demirel Y 2014 Nonequilibrium Thermodynamics, 3rd edn. Amsterdam: Elsevier, pp. 119-160

[14] Honig J M 2014 Thermodynamics, 4th edn. Amsterdam: Elsevier: 337-356

[15] Prigogine I 1967 Introduction to Thermodynamics of Irreversible Processes, 3rd edn. New York: Wiley, pp. 40-54

[16] Onsager L 1931 Reciprocal relations in irreversible processes. Phys. Rev. 38: 2265-2279 